\section{Commentary: New onset atrial fibrillation: Not just a nuisance}

\author{
Stacey Chen, MD, and Eugene A. Grossi, MD
}

Atrial fibrillation (AF) is a common complication following cardiac surgery. ${ }^{1,2}$ Although often selflimiting, postoperative $\mathrm{AF}$ is associated with significant morbidity and mortality. ${ }^{1-3}$ In this issue of the Journal, Björn and colleagues ${ }^{4}$ present a multi-institutional retrospective study evaluating the incidence of new-onset AF (NOAF) and long-term outcomes in 782 patients with no history of AF who underwent isolated surgical aortic valve replacement (SAVR). Both bioprosthetic and mechanical AVRs were included in the overall study, with subset analyses performed for bioprosthetic and mechanical valves. The authors report that $42.6 \%$ of patients developed inhospital NOAF and $32 \%$ developed late AF, defined as either AF after hospital discharge or NOAF persisting for at least 3 months. In the overall cohort, mitral valve regurgitation degree $\geq \mathrm{III}$ and NOAF were independent predictors of late $\mathrm{AF}$, while left atrial dilatation was an independent risk factor in the overall and bioprosthetic groups. Importantly, this study reflects long-term followup in NOAF patients with a median follow-up of 5.4 years. Björn and colleagues demonstrate that although NOAF in SAVR patients was not associated with increased incidence of stroke, it was associated with increased AF recurrence years after patients' index AVR and all-cause mortality in a risk-adjusted model.

In a recent study evaluating preoperative predictors of NOAF in 720 patients undergoing isolated SAVR, Axtell and associates ${ }^{5}$ reported that NOAF persisted for up to 5.5 years in their study cohort. The influence of NOAF in

From the Department of Cardiothoracic Surgery, NYU Langone Health, New York, NY.

Disclosures: The authors reported no conflicts of interest.

The Journal policy requires editors and reviewers to disclose conflicts of interest and to decline handling or reviewing manuscripts for which they may have a conflict of interest. The editors and reviewers of this article have no conflicts of interest.

Received for publication April 7, 2021; revisions received April 7, 2021; accepted for publication April 7, 2021; available ahead of print April 20, 2021.

Address for reprints: Eugene A. Grossi, MD, Department of Cardiothoracic Surgery, NYU Langone Health, 530 First Ave, Suite 9V, New York, NY 10016 (E-mail: eugene.grossi@nyulangone.org).

J Thorac Cardiovasc Surg 2022;164:1844-5

$0022-5223 / \$ 36.00$

Copyright (c) 2021 by The American Association for Thoracic Surgery

https://doi.org/10.1016/j.jtcvs.2021.04.010

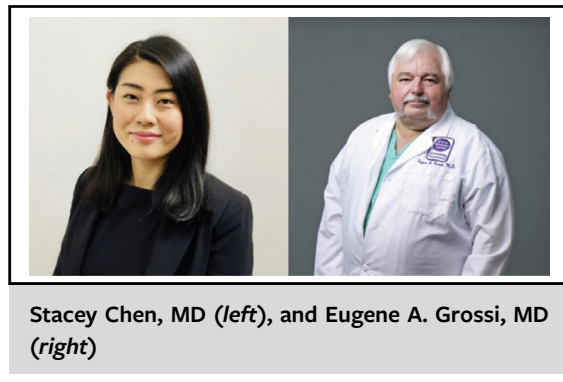

CENTRAL MESSAGE

Surgical aortic valve replacement complicated by new-onset atrial fibrillation is associated with poor long-term outcomes. Studies of prophylactic left atrial appendage exclusion may be warranted.

long-term outcomes in SAVR patients from these recent studies highlight the importance of adjunctive measures to prevent NOAF. ${ }^{4,5}$ The left atrial appendage (LAA) serves as the nidus of atrial thrombi in $90 \%$ of patients. ${ }^{6}$ Although some studies have focused on the concept of LAA exclusion to decrease stroke risk in AF patients, data are lacking on routine LAA exclusion with concomitant cardiac surgery in patients without a known history of $\mathrm{AF}^{7,8}$ As such, further investigation regarding the role of LAA exclusion as a prophylactic strategy to decrease the incidence of NOAF is a growing area of interest. Indeed, the AtriClip LAA Exclusion Concomitant to Structural Heart Procedures trial (ATLAS; ClinicalTrials.gov identifier NCT02478294) is the first prospective randomized multicenter trial that will compare patients without pre-existing $\mathrm{AF}$ with $\mathrm{CHA}_{2} \mathrm{DS}_{2}$-VASc (congestive heart failure, hypertension, age $\geq 75$ years, diabetes mellitus, previous history of stroke or transient ischemic attack, vascular disease, age 65-74 years, female sex) score $\geq 2$ in two treatment arms: patients who undergo valve or coronary artery bypass graft surgery with and without LAA exclusion. Data from this trial will provide valuable information regarding the potential role for routine prophylactic LAA exclusion.

The long-term clinical sequelae of NOAF in SAVR patients reported by Björn and colleagues demonstrate that we can no longer disregard NOAF. Serious consideration for strategies to prevent NOAF occurrence to improve 
long-term outcomes in this high-risk patient population are warranted.

\section{References}

1. Greenberg JW, Lancaster TS, Schuessler RB, Melby SJ. Postoperative atrial fibrillation following cardiac surgery: a persistent complication. Eur J Cardiothorac Surg. 2017;52:665-72.

2. Rostagno C, La Meir M, Gelsomino S, Ghilli L, Rossi A, Carone E, et al. Atrial fibrillation after cardiac surgery: incidence, risk factors, and economic burden. $J$ Cardiothorac Vasc Anesth. 2010;24:952-8.

3. LaPar DJ, Speir AM, Crosby IK, Fonner E Jr, Brown M, Rich JB, et al. Postoperative atrial fibrillation significantly increases mortality, hospital readmission, and hospital costs. Ann Thorac Surg. 2014;98:527-33; discussion 533.

4. Björn R, Nissinen M, Lehto J, Malmberg M, Yannopoulos F, Juhani Airaksinen KE, et al. Late incidence and recurrence of new-onset atrial fibrillation after isolated surgical aortic valve replacement. J Thorac Cardiovasc Surg. 2022; 164:1833-43.e4.

5. Axtell AL, Moonsamy P, Melnitchouk S, Tolis G, Jassar AS D'Alessandro DA, et al. Preoperative predictors of new-onset prolonged atrial fibrillation after surgical aortic valve replacement. J Thorac Cardiovasc Surg. 2020;159:1407-14.

6. Blackshear JL, Odell JA. Appendage obliteration to reduce stroke in cardiac surgical patients with atrial fibrillation. Ann Thorac Surg. 1996;61:755-9.

7. Emmert MY, Puippe G, Baumüller S, Alkadhi H, Landmesser U, Plass A et al. Safe, effective and durable epicardial left atrial appendage clip occlusion in patients with atrial fibrillation undergoing cardiac surgery: first long-term results from a prospective device trial. Eur J Cardiothorac Surg. 2014;45:126-31.

8. Bedeir K, Holmes DR, Cox JL, Ramlawi B. Left atrial appendage exclusion: an alternative to anticoagulation in nonvalvular atrial fibrillation. $J$ Thorac Cardiovasc Surg. 2017;153:1097-105.
See Article page 1833.

\section{Commentary: Postoperative atrial fibrillation: An old foe in a new light}

\author{
Moritz C. Wyler von Ballmoos, MD, PhD, MPH, ${ }^{\mathrm{a}, \mathrm{b}}$ \\ and G. Hossein Almassi, MD ${ }^{\mathrm{c}, \mathrm{d}}$
}

Postoperative atrial fibrillation (POAF) continues to plague the work of cardiac surgeons as one of the most commonly reported complications. Although often self-limited and partially preventable, ${ }^{1}$ the reported incidence after bypass and valve surgery is as high as $40 \%{ }^{2}$

In this edition of the Journal, Björn and colleagues ${ }^{3}$ report their results on 782 patients undergoing isolated surgical aortic valve replacement (SAVR), the incidence of new-onset atrial fibrillation (NOAF), persistence of atrial fibrillation after hospital discharge, and associated mortality over a median follow-up of 5.4 years. Of note, all patients in their cohort received

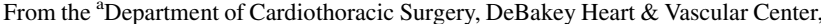
Houston, Tex; ${ }^{b}$ Weill Cornell Medicine, New York, NY; ${ }^{\mathrm{c} D i v i s i o n}$ of Cardiothoracic Surgery, Department of Surgery, Medical College of Wisconsin, Milwaukee, Wis; and ${ }^{\mathrm{d}}$ Zablocki Veterans Affairs Medical Center, Milwaukee, Wis.

Disclosures: The authors reported no conflicts of interest.

The Journal policy requires editors and reviewers to disclose conflicts of interest and to decline handling or reviewing manuscripts for which they may have a conflict of interest. The editors and reviewers of this article have no conflicts of interest.

Received for publication April 7, 2021; revisions received April 7, 2021; accepted for publication April 9, 2021; available ahead of print April 16, 2021.

Address for reprints: G. Hossein Almassi, MD, Division of Cardiothoracic Surgery, Medical College of Wisconsin, 8701 Watertown Plank Rd, Milwaukee, WI

53226 (E-mail: halmassi@mcw.edu).

J Thorac Cardiovasc Surg 2022;164:1845-6

$0022-5223 / \$ 36.00$

Copyright (c) 2021 by The American Association for Thoracic Surgery

https://doi.org/10.1016/j.jtcvs.2021.04.021
}

\section{Check for updates}

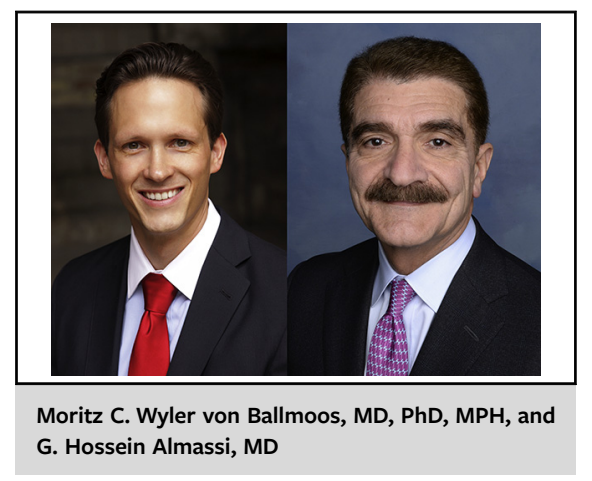

CENTRAL MESSAGE

Postoperative atrial fibrillation

(POAF) portends an increased

risk of long-term mortality after

aortic valve replacement. The

extent to which POAF directly

causes morbidity and mortality

remains to be determined.

perioperative and postoperative beta-blocker medication. In addition, all patients, including those receiving a bioprosthetic valve, were received routine anticoagulation with a vitamin $\mathrm{K}$ antagonist for at least 90 days postoperatively.

A documented episode of atrial fibrillation of $10 \mathrm{mi}-$ nutes or longer was used to define NOAF, which had an incidence of $42 \%$ during the index hospitalization and $32 \%$ in the outpatient setting, with a higher incidence in patients receiving a bioprosthetic valve, who 